\title{
Genetic Analyses Suggest Separate Introductions of the Pine Pathogen Lecanosticta acicola Into Europe
}

\author{
Josef Janoušek, Michael J. Wingfield, José G. Marmolejo Monsivais, Libor Jankovský, Christian Stauffer, \\ Adam Konečný, and Irene Barnes
}

First and fourth authors: Department of Forest Protection and Wildlife Management, Faculty of Forestry and Wood Technology, Mendel University in Brno, Brno 613 00, Czech Republic; second and seventh authors: Department of Genetics, Forestry and Agricultural Biotechnology Institute (FABI), University of Pretoria, Pretoria 0002, South Africa; third author: Facultad de Ciencias Forestales, UANL, Nuevo León 67700, Mexico; fifth author: Department of Forest and Soil Sciences, University of Natural Resources and Life Sciences, Vienna 1190, Austria; and sixth author: Department of Botany and Zoology, Faculty of Science, Masaryk University, Brno 625 00, Czech Republic. Accepted for publication 14 December 2015.

\begin{abstract}
Janoušek, J., Wingfield, M. J., Marmolejo Monsivais, J. G., Jankovský, L., Stauffer, C., Konečný, A., and Barnes, I. 2016. Genetic analyses suggest separate introductions of the pine pathogen Lecanosticta acicola into Europe. Phytopathology 106:1413-1425.

Lecanosticta acicola is a heterothallic ascomycete that causes brown spot needle blight on native and nonnative Pinus spp. in many regions of the world. In this study we investigated the origin of European L. acicola populations and estimated the level of random mating of the pathogen in affected areas. Part of the elongation factor $1-\alpha$ gene was sequenced, 11 microsatellite regions were screened, and the mating type

species of Lecanosticta. The isolates from East Asia formed a uniform and discrete group. Two distinct populations were identified in both North America and Europe. Approximate Bayesian computation analyses strongly suggest independent introductions of two populations from North America into Europe. Microsatellite data and mating type distributions indicated random recombination in the populations of North America and Europe. Its intercontinental introduction can most likely be explained as a consequence of the movement of infected plant material. In contrast, the spread of L. acicola within Europe appears to be primarily due to conidial dispersion and probably also ascospore dissemination.
\end{abstract} idiomorphs were determined for 201 isolates of L. acicola collected from three continents and 17 host species. The isolates from Mexico and Guatemala were unique, highly diverse and could represent cryptic
Additional keywords: fungus, haploid, Mycosphaerella dearnessii, population genetics, reproductive mode.
Increasing human activity related to globalization and climate change is increasing the risks of biological invasions by plant pathogens (Grünwald and Goss 2011; Wingfield et al. 2011). Such biological invasions by fungal pathogens have already resulted in diseases that have modified environments and reduced natural biodiversity (Desprez-Loustau et al. 2007; Fisher et al. 2012; Garbelotto 2008). In this regard, there is considerable concern for the long-term preservation of sensitive forest ecosystems (Boyd et al. 2013; Wingfield et al. 2015) especially since invasions by forest pathogens have been increasing exponentially in Europe during the last four decades (Santini et al. 2013). Serious consequences of such introductions into new environments are well documented, e.g., ash dieback in Europe caused by Hymenoscyphus fraxineus (Gross et al. 2014) and Phytophthora ramorum that causes sudden oak death of oak and tanoak in native forests in North America, and a rampant nursery disease known as Ramorum blight (Eyre and Garbelotto 2015). It is, therefore, important to correctly identify fungal pathogens and to understand the processes underpinning introductions into new environments.

Population genetics can provide a reliable means to identify and understand the invasion history of plant pathogens (Giraud et al.

Corresponding author: J. Janoušek; E-mail address: janousek.jose@gmail.com

L. Jankovský, C. Stauffer, A. Konečný, and I. Barnes contributed equally to this manuscript.

*The $e$-Xtra logo stands for "electronic extra" and indicates that three supplementary figures and five supplementary tables are published online.

http://dx.doi.org/10.1094/PHYTO-10-15-0271-R

(C) 2016 The American Phytopathological Society
2008; Grünwald and Goss 2011). In this regard, a statistical method receiving increasing attention is approximate Bayesian computation (ABC) (Beaumont et al. 2002, 2010). ABC is a statistical framework that calculates the relative probabilities of complex, competing models of evolutionary history of populations and estimates the demographic parameters underlying a given model (Bertorelle et al. 2010; Sunnåker et al. 2013). This approach can be used to reconstruct the demographic history of invasive species (Boissin et al. 2012; Guillemaud et al. 2010; Konečný et al. 2013), including fungal plant pathogens (Dilmaghani et al. 2012; Dutech et al. 2012).

Mode of reproduction plays an essential role in the genetic diversity of ascomycetes and in their infection biology (McDonald and Linde 2002; Milgroom 1996). The presence of sexual reproduction in a population can reflect the ability of the pathogen to become invasive in a new environment because it has an influence on pathogen overwintering, dissemination, infection biology, and its ability to adapt to environmental conditions (Barrett et al. 2008; Bazin et al. 2014; Giraud et al. 2008). It is, however, commonly difficult to detect sexual recombination in a fungal population where this mode of reproduction is cryptic or facultative (Milgroom 1996; Saleh et al. 2012). To overcome this obstacle, the distribution of the mating type idiomorphs can be determined in a given population. The presence of both idiomorphs at approximately equal frequencies suggests that regular sexual reproduction is occurring, while presence of single idiomorph would indicate the population is undergoing asexual reproduction (Barnes et al. 2014; Linde et al. 2003; Taylor 1999).

Lecanosticta acicola (Thüm.) Syd. is a heterothallic (Janoušek et al. 2014) ascomycete that causes brown spot needle blight on 
pines. The pathogen is reported to infect more than 30 pine species, variable levels of susceptibility being reported across and within pine species (Sinclair and Lyon 2005; Tainter and Baker 1996). Severe infection of needles by L. acicola can lead to retardation of growth and death of trees (Kais 1975). The pathogen reproduces asexually via conidia that are dispersed predominantly by rain splash and dew. Sexual ascospores are dispersed primarily in air currents over long distances (Kais 1971; Siggers 1944; Wolf and Barbour 1940). Little is known, however, regarding the extent to which sexual reproduction contributes to the life cycle or to the spread of brown spot needle blight in affected regions.

Brown spot needle blight has been known on Pinus palustris and other pine species in the south and southeastern United States since the 19th century where it has been an important constraint to P. palustris seedling regeneration (Sinclair and Lyon 2005; Thümen 1878). In the northern parts of North America, brown spot needle blight occurs predominantly on native $P$. strobus and nonnative P. sylvestris (Boyce 1959; Laflamme et al. 2010; Stanosz 1990). In Central America and Mexico, L. acicola has been described from sea-level tropical forests up to high altitude forests (Evans 1984; Alonso and Perez 1987) on native pine species. In South America, it is has been reported from only nonnative pine plantations in Colombia (Gibson, 1980). In Europe, L. acicola was first reported in Spain in the 1940s (Martínez 1942) and later, in former Yugoslavia, France and in Central Europe (Jankovský et al. 2009; Lévy and Lafaurie 1994; Milatović 1976). It is currently listed as a quarantine pathogen by the European Plant Protection Organization (EPPO) (Pehl et al. 2015). L. acicola also causes severe defoliation of nonnative pines in China (Huang et al. 1995) where it was suggested, based on rapid amplified polymorphic DNA (RAPD) marker analyses, that the pathogen was introduced from the southern United States. However, the origin of the pathogen in Europe and other regions of the world remains unknown.

The objective of this study was to consider the origin of European populations of L. acicola and to estimate the opportunities for its sexual reproduction in screened populations. More specifically, we (i) investigated the intraspecific variability of L. acicola on a global scale, (ii) determined the genetic structure and diversity of populations, (iii) deciphered the historico-demographical relationships between North American and European populations, and (iv) determined and compared levels of random mating in studied populations of L. acicola. Part of the elongation factor (EF) gene was sequenced, 11 microsatellites were screened, and the mating type idiomorphs were determined for populations of isolates collected from three continents and 17 pine species.

\section{MATERIALS AND METHODS}

Sample collection, isolation, DNA extraction, and isolate identification. Needle samples with developed fruiting bodies of L. acicola were collected randomly from individual trees by authors or obtained from colleagues (for details about location and number of isolates, see Table 1 and Supplementary Table S1). Samples were collected from the Americas (Colombia, Guatemala, Mexico, the United States, and Canada), 11 European countries, China, South Korea, and Japan.

Needle samples were stored at $-80^{\circ} \mathrm{C}$ to prevent their deterioration and to kill mite and insect contaminants. Needles with developed fruiting bodies and showing Lecanosticta-like discoloration were selected for isolation and conidia were isolated as previously described by Barnes et al. (2004). All isolates were cultivated on $2 \%$ malt-extract agar media with yeast extract (5 g/liter) for 3 to 6 weeks. Isolates showing typical Lecanosticta-like morphology (Pehl et al. 2015) were chosen for DNA extraction and DNA-based species identification.

Fungal mycelium was transferred to Eppendorf tubes and lyophilized for several hours to facilitate subsequent homogenization.
DNA was extracted using the PowerSoil DNA Isolation Kit (12888; MoBio, Carlsbad, CA), eluted with $100 \mu$ l of elution buffer following the manufacturer's instructions, and stored at $-20^{\circ} \mathrm{C}$.

DNA-based identification was performed for each isolate with species-specific primers LAtef-F/R as described by Ioos et al. (2010). Isolates testing positive for L. acicola amplified a product of $237 \mathrm{bp}$ with this primer set. PCR products were visualized on $2 \%$ agarose gel stained with GelRed (Hayward, CA).

DNA sequencing, intraspecific variation and phylogenetic analyses. The EF region of 87 selected isolates from different locations was PCR amplified using EF primers EF1/2 (Jacobs et al. 2004). PCR was performed using $2 \mathrm{mM} \mathrm{MgCl} 2,100 \mu \mathrm{M}$ dNTPs, $0.2 \mu \mathrm{M}$ of the primers, $0.2 \mathrm{U}$ of Taq polymerase (Fermentas, Vilnius, Lithuania), $1 \times\left(\mathrm{NH}_{4}\right)_{2} \mathrm{SO}_{4}$ buffer (Fermentas), $2.0 \mu \mathrm{l}$ of genomic DNA (gDNA), and $\mathrm{H}_{2} \mathrm{O}$ to $20 \mu \mathrm{l}$ volume. The PCR profile was as follows: $94^{\circ} \mathrm{C}$ for $10 \mathrm{~min}, 35$ cycles at $94^{\circ} \mathrm{C}$ for $30 \mathrm{~s}, 58^{\circ} \mathrm{C}$ for $45 \mathrm{~s}, 72^{\circ} \mathrm{C}$ for $60 \mathrm{~s}$, and $72^{\circ} \mathrm{C}$ for $10 \mathrm{~min}$. Correct amplification was verified by gel electrophoresis as described above, and the amplicons were custom-sequenced at the Cancer Research Center DNA Sequencing Facility (University of Chicago, Chicago).

Sequence data were edited using BIOEDIT v7.2.0. (Hall 1999) and aligned using MAFFT v. 7 (Katoh et al. 2002; Katoh and Standley 2013). Additional EF sequences were retrieved from GenBank and included in the analyses: JX901650 (L. guatemalensis; Guatemala; IMI 281598), JX901651 and JX901652 (L. longispora; Mexico; CBS 133789, CPC 17940), JX901648 (L. acicola; Mexico; CBS 133789), JX901647 (L. acicola; France; LNPV 243), KT737239 (L. acicola; France; CBS 871.95), and KC013002 (United States; CBS 133791)epitype of L. acicola (Quaedvlieg et al. 2012). Sequence data sets were compiled using MEGA 5.2 (Tamura et al. 2011) and EF haplotypes were defined using TCS 1.21 software (Clement et al. 2000). Sequences of isolates representing each EF haplotype were submitted to GenBank and their alignment to TreeBASE (http:// purl.org/phylo/treebase/phylows/study/TB2:S18403).

Nucleotide diversity $(\mathrm{Pi})$ was calculated for selected groups of EF haplotypes using DnaSP v5 (Librado and Rozas 2009). Medianjoining haplotype network was constructed using program Network 4.613 (http://www.fluxus-engineering.com/sharenet.htm) (Bandelt et al. 1999) to depict relationships among different EF haplotypes.

Phylogenetic analyses were done using maximum parsimony (MP), maximum likelihood (ML), and Bayesian inference (BI) and results visualized in MEGA 5.2. MP analyses were performed using PAUP 4.0b10 (Swofford 2003). Random stepwise addition heuristic searches were performed with tree-bisection-reconnection branchswapping. Alignment gaps were considered as a fifth character state and confidence was estimated by performing 1,000 bootstrap replications (Felsenstein 1985) with simple sequence addition.

For the ML analyses, the nucleotide substitution model with the best likelihood for the data set was selected with jModelTest v2.1.1 (Darriba et al. 2012; Guindon and Gascuel 2003) using the Akaike information criterion. ML analyses were carried out in PhyML 3.0 (Guindon et al. 2010). Confidence levels were estimated from 1,000 bootstrap replicates.

BI analysis was performed with MrBayes 3.1.2 (Ronquist and Huelsenbeck 2003) running $3 \times 10^{6}$ Markov Chain Monte Carlo (MCMC) generations. Four runs were performed and trees were sampled every 100th generation. The generalized time reversible substitution model with gamma-distributed rate variation across sites and the proportion of invariable sites was selected. The burn-in value was determined with TRACER v1.5 (Rambaut and Drummond 2007) (http://tree.bio.ed.ac.uk/software/tracer/) and the log-likelihood scores of sampled trees were plotted against the generation time to compare the results of each run. Nodes with a posterior probability $\geq 0.95$ were considered to be significantly supported by the data.

Microsatellite genotyping. All isolates except those from Asia, South America, Guatemala, and Mexico were screened with 
11 microsatellite markers. PCR amplification of the microsatellite regions was performed as described in Janoušek et al. (2014) with the exception of the annealing temperature for primer set MD6 and MD8 being increased to $63^{\circ} \mathrm{C}$ to reduce stutter bands. Annealing temperatures were decreased for the isolates originating from Mexico and Guatemala as follows: $54^{\circ} \mathrm{C}$ for MD1, 5, 9, 10 primer sets and to $56^{\circ} \mathrm{C}$ for primer set MD8. Correct amplification was verified by gel electrophoresis on a subset of samples. Amplicons were pooled into two panels (Janoušek et al. 2014) for fragment analysis on an ABI 3730XL (Applied Biosystems) and sized with LIZ 500 size standard (Applied Biosystems). Lengths of alleles were scored using GeneMapper 4.1 (Applied Biosystems). Isolates from the same location with identical multilocus haplotypes (MLHs) were considered as clones and excluded for selected analyses (clonecorrected data set).

Analyses of population structure. The program STRUCTURE 2.3.4 was used to identify genetically different subpopulations within and between North American and European isolates. Using a model-based clustering method, the most likely number of genetic groups (K), was determined by employing a Bayesian MCMC clustering algorithm (Falush et al. 2003; Hubisz et al. 2009; Pritchard et al. 2000).

The full clone-corrected haploid data set was analyzed running $2 \times 10^{5}$ burn-in iterations followed by $6 \times 10^{5} \mathrm{MCMC}$ iterations. The model with correlated allele frequencies and allowing admixture was selected. Thirty replicates for each K (1 to 6) were

TABLE 1. Information on Lecanosticta acicola isolates used in this study: number of isolates per location, geographic origin of the isolates, and host species

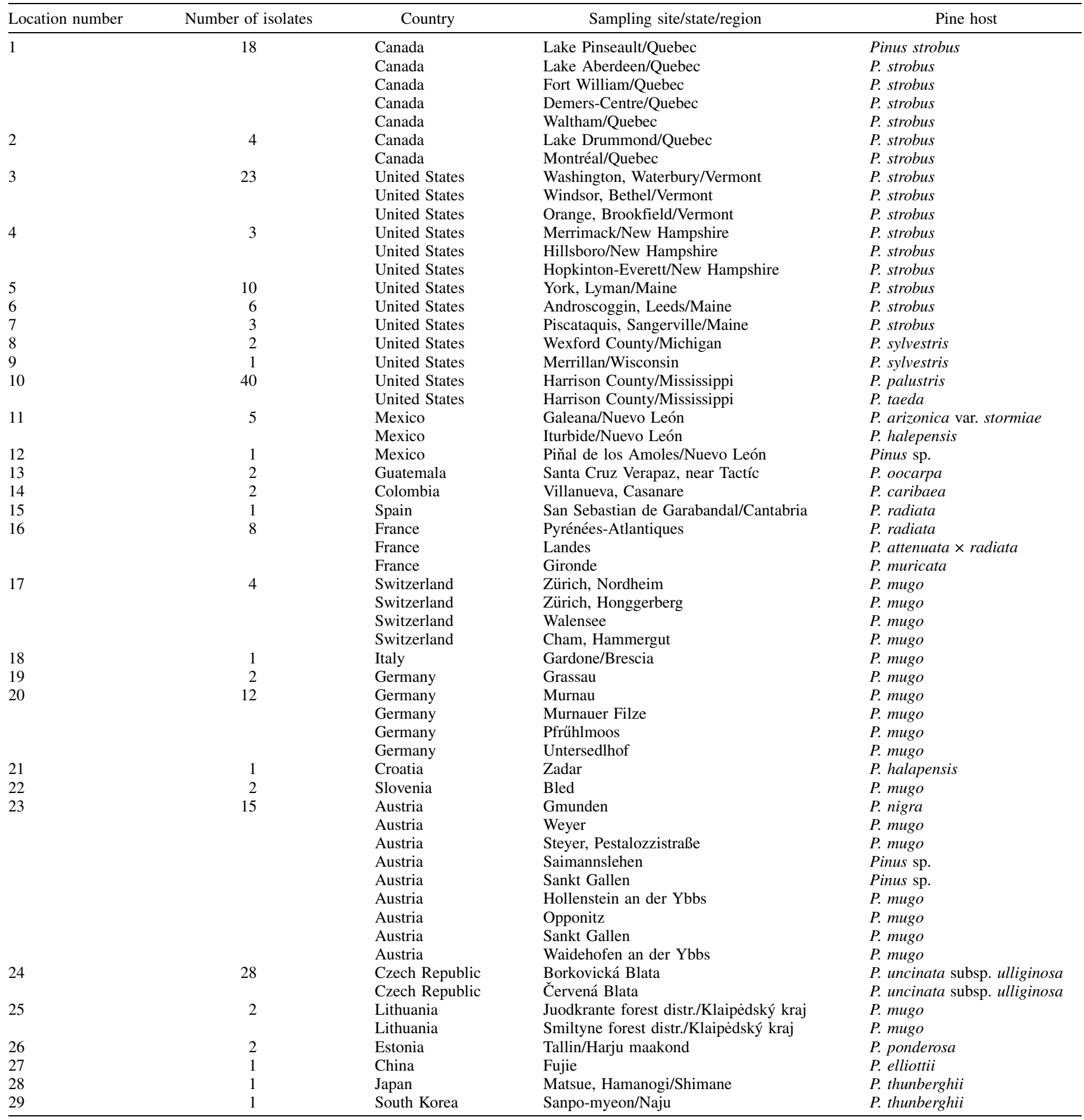


performed to increase the precision of the parameter estimates and to reduce the effect of stochasticity of the MCMC algorithm (Excoffier and Heckel 2006). The analysis was repeated on a subset of isolates representing a cluster identified in the first run, employing nine polymorphic markers (two loci were monomorphic within blue group). STRUCTURE HARVESTER (Earl and vonHoldt 2012) was used online to generate input files of each $\mathrm{K}$ for CLUMPP v1.1.2 (Jakobsson and Rosenberg 2007). CLUMPP was used to identify potential dissimilar solutions among the results of individual STRUCTURE runs for each K. For this purpose, the Greedy algorithm implemented in CLUMPP was used to calculate the pair-wise symmetric similarity coefficient (SSC) to identify similar runs (SSC $>0.9$ ) of each $\mathrm{K}$. The averaged results for similar runs from CLUMPP were then used to generate summary bar plots for each K with DISTRUCT version 1.1 (Rosenberg 2004).

Complementary to the Bayesian analysis, principal component analysis (PCA) was conducted on the clone-corrected data set. PCA presents genotypes in a multivariate space described by the principal components and it does not rely on any population genetic model (Jombart et al. 2009; McVean 2009). The analysis was performed using GENETIX v. 4.0.5.2 (Belkhir et al. 1996-2004) (http://kimura.univ-montp2.fr/genetix/). As in the STRUCTURE analyses, the full data set with all microsatellite loci was analyzed first and then repeated using only the isolates identified in the northern cluster with nine microsatellite loci. PCA graphics were visualized by two principal components as recommended by Jombart et al. (2009).

Genetic differentiation was calculated between pairs of genetic STRUCTURE and PCA-defined populations (CE, central and north Europe; MS, Mississippi; NA, northeast North America; and SE, southwest Europe) using FSTAT v2.9.3.2 (Goudet 2002). Additionally, hierarchical analyses of molecular variance (AMOVA) (Excoffier et al. 1992) implemented in GenAlEx 6.5 (Peakall and Smouse 2006, 2012) were performed to investigate the relative contributions of host species and geographic origin to the partitioning of genetic variance. The non-clone-corrected microsatellite data set of the European isolates was used for AMOVA and isolates originating from unknown pine species were excluded. All data were treated as haploid-SSR and permutation tests were performed with 9,999 random permutations of haplotypes.

Genetic diversity in populations. The isolates were divided into four STRUCTURE and PCA-defined populations for genetic diversity analyses (CE, MS, NA, and SE) (Table 2). Furthermore, isolates were divided based on their geographic origin: isolates more than $100 \mathrm{~km}$ apart were divided into separate groups (Table 2, Fig. 1). Although in some cases, only one or two isolates represented a single location, these isolates were included in the analyses of populations representing larger geographic areas. Isolates from Asia and South America were excluded as the sample size was inordinately low. Isolates from Mexico and Guatemala amplified poorly at most loci and thus were excluded from the analyses.

The number of MLHs was calculated for each population and location. The clonal fraction (CF) was calculated as $1-[$ (number of different haplotypes)/(total number of isolates)] (Zhan et al. 2003). Genotypic diversity $(G)$, defined as the probability that two individuals taken at random have different haplotypes, was

TABLE 2. Genetic differentiation $\left(\mathrm{F}_{\mathrm{ST}}\right)$ between pairs of genetically defined clusters of Lecanosticta acicola populations ${ }^{\mathrm{a}}$

\begin{tabular}{lccc}
\hline & MS & NA & CE \\
\hline NA & 0.481 & & \\
CE & 0.471 & 0.286 & \\
SE & 0.351 & 0.662 & 0.642 \\
\hline
\end{tabular}

a Abbreviations of populations: CE, central and northern European population; MS, Mississippi population; NA, northeastern North American population; and SE, southwestern European population. calculated on non-clone-corrected data sets using MULTILOCUS v1.3 (Agapow and Burt 2001). Number of alleles $\left(N_{a}\right)$ and allelic richness $\left(A_{R}\right)$ were calculated using FSTAT. Gene diversity was estimated over all loci for each population and location by calculating unbiased expected heterozygosity $\left(H_{e}\right)$ (Nei 1978) in GENETIX.

Migration scenarios. The approximate Bayesian computation (ABC) framework was used to elucidate the demographic history of the North American and European populations of L. acicola. All $\mathrm{ABC}$ analyses were performed on clone-corrected microsatellite data using the program DIYABC v.2.0.4 (Cornuet et al. 2014), which allows inferences to be made on the demographic history of populations of haploid species. Only the markers constituting perfect microsatellite repeat motifs were used for the ABC analyses. These included seven makers, namely MD1, MD2, MD4, MD7, MD8, MD9, and MD12.

The evolutionary scenarios were drawn based on four STRUCTURE and PCA-defined genetic clusters (CE, MS, NA, and $\mathrm{SE}$ ). In total, six different scenarios were tested to compare the different evolutionary scenarios. Prior distributions of the demographic parameters were defined as uniform and with a broad range, due to a very limited knowledge of $L$. acicola population history.

The default settings for the mutational parameters of microsatellites, rates and modalities of mutation were used in DIYABC software, as these settings are commonly used for most eukaryotes (Cornuet et al. 2014). Each locus was assumed to follow a generalized stepwise mutation model (GSM) (Estoup et al. 2002) with a possible range of 40 contiguous allelic states. The allelic range was extended to 63 allelic states for locus MD8. The genetic variation within and between populations was summarized using a set of 'one sample summary statistic' (mean number of alleles, mean size variance) and 'two sample summary statistics' (mean genic diversity, $\mathrm{F}_{\mathrm{ST}}$, classification index, $(\delta \mu)^{2}$ distance)-as described in the DIYABC manual available at http://www1. montpellier.inra.fr/CBGP/diyabc/index.php. For each scenario, $10^{6}$ data sets were simulated.

All scenarios tested were first compared by their relative posterior probabilities using polychotomous logistic regression from $1 \%$ of the closest simulated data sets to the observed one in a multidimensional space of summary statistics, which were transformed by linear discriminant analysis (LDA) (Estoup et al. 2012). The scenario with the significantly highest posterior probability value (95\% confidence interval) was selected as best. Secondly, posterior distributions of parameters were estimated for the most likely scenario by the logit transformation of parameters and linear regression on $1 \%$ of the closest simulated data sets.

Confidence in scenario choice was evaluated based on sets of 200 pseudo-observed data sets (pods), obtained by simulations for each scenario with parameter values taken from given distributions. The same number of loci and individuals as real data set was tested. The relative posterior probabilities of each competing scenario were estimated for each pod using LDA-transformed summary statistics. These probabilities were further used to calculate the type I and II errors for the scenarios chosen with our real data set. Type I error (false positives) is the probability of excluding the selected scenario when it is the true scenario. Type II error (false negatives) is the probability of selecting the scenario when it is not the true scenario (mean of type II error was calculated over the competing scenarios).

The goodness-of-fit of the best scenario was evaluated using the "model checking" option. This analysis allows an evaluation of the extent to which the selected scenario and associated posterior distribution are supported by the observed L. acicola genetic data. The summary statistics, which were not used in the previous analyses, were used for model checking as recommended by Cornuet et al. (2010).

Reproductive mode. The mating type idiomorph for each isolate was determined using multiplex PCR runs in $6 \mu \mathrm{l}$ volumes consisting of $2.5 \mathrm{mM} \mathrm{MgCl}_{2}, 100 \mu \mathrm{M}$ dNTPs, $0.2 \mu \mathrm{M}$ of each MAT 
specific primer (Janoušek et al. 2014), $0.2 \mathrm{U}$ of Taq polymerase (Fermentas), $1 \times\left(\mathrm{NH}_{4}\right)_{2} \mathrm{SO}_{4}$ buffer (Fermentas), $0.8 \mu \mathrm{l}$ of gDNA, and $\mathrm{H}_{2} \mathrm{O}$. The PCR products were visualized using gel electrophoresis and the idiomorph of each isolate was determined based on the expected size of $634 \mathrm{bp}$ for MAT1-1-1 and $323 \mathrm{bp}$ for MAT1-2. The distribution of the mating type idiomorphs in the populations was calculated and an exact binomial test was performed using the program STATISTICA 10 (StatSoft CR s.r.o.) to determine whether populations/sampled locations deviated from the null hypothesis of a 1:1 ratio of random mating (McDonald 2009).

Clone-corrected data-based parsimony tree-length permutation tests (PTLPT) (Burt et al. 1996) and multilocus linkage disequilibrium analyses were performed to test for random mating among isolates from selected locations. In the populations where random mating occurred, the expected parsimony tree length would be substantially longer. In contrast, a clonally reproducing population would produce one well-resolved, significantly shorter tree. The data sets were generated using MULTILOCUS v1.3 (Agapow and Burt 2001) and analyzed using PAUP 4.0b10 (Swofford 2003). To assess the statistical significance associated with the null hypothesis of random mating, 1,000 randomizations were performed. MULTILOCUS v1.3 was used to calculate the standardized index of association, expressed by $r B a r D$, which is sample size independent (Agapow and Burt 2001). Data sets were randomized 10,000 times. The observed values of $r B a r D$ were compared with the values of the randomized data sets. If the observed value was significantly different from the randomized data set $(P \leq 0.05)$, the null hypothesis was rejected. In contrast, if observed and randomized data sets were not significantly different, this indicated that the analyzed population is undergoing random mating.

\section{RESULTS}

Sample collection, isolations, DNA extractions, and isolate identification. Isolates that showed morphologies typical of Lecanosticta were obtained from infected needles and DNA was extracted from these isolates. In total, 201 isolates were identified as L. acicola. Twenty-two isolates originated from the southeast of Canada, 88 isolates from six states in the United States, 78 isolates from 11 countries in Europe, three isolates from Asia (China, South Korea, and Japan), eight isolates from Mexico and Guatemala, and two isolates from South America (Colombia). Overall, the isolates originated from 17 pine species collected from three continents (Table 1, Fig. 1). All isolates are maintained in the culture collection of the Department of Forest Protection and Wildlife Management, Mendel University in Brno, Czech Republic and/or in the culture collection (CMW) of the Forestry and Agricultural Biotechnology Institute (FABI), University in Pretoria, South Africa.

DNA sequencing, intraspecific variation, and phylogenetic analyses. Partial EF amplicons of about 900 bp were sequenced and 14 haplotypes were identified in 87 isolates originating from America, Europe, and Asia (Fig. 1). All eight isolates from Mexico and Guatemala revealed a nucleotide diversity of $\mathrm{Pi}=$ 0.0356 . For all other regions, the nucleotide diversity was considerably lower with the next highest diversity found in Mississippi $(\mathrm{Pi}=0.0039)$ where four haplotypes were identified
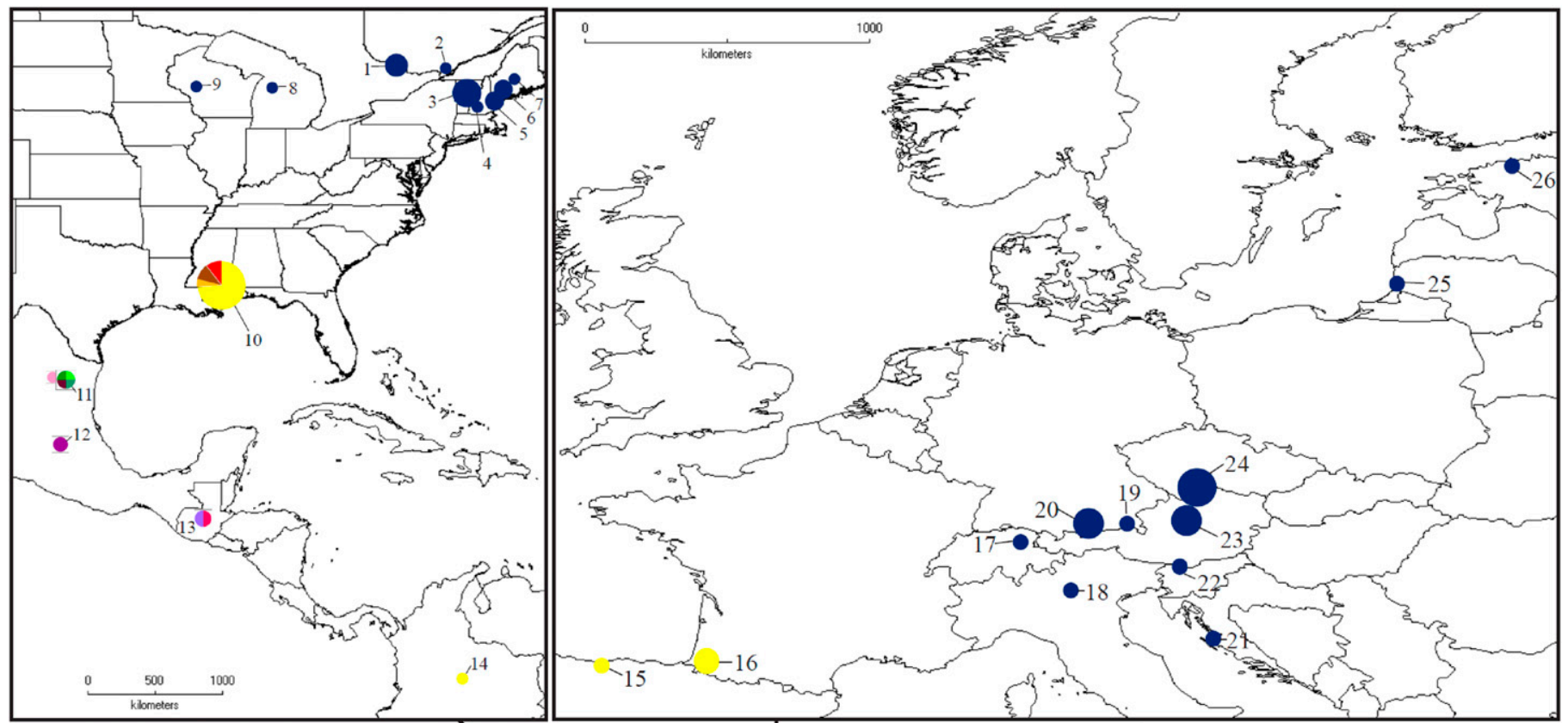

Population sample size
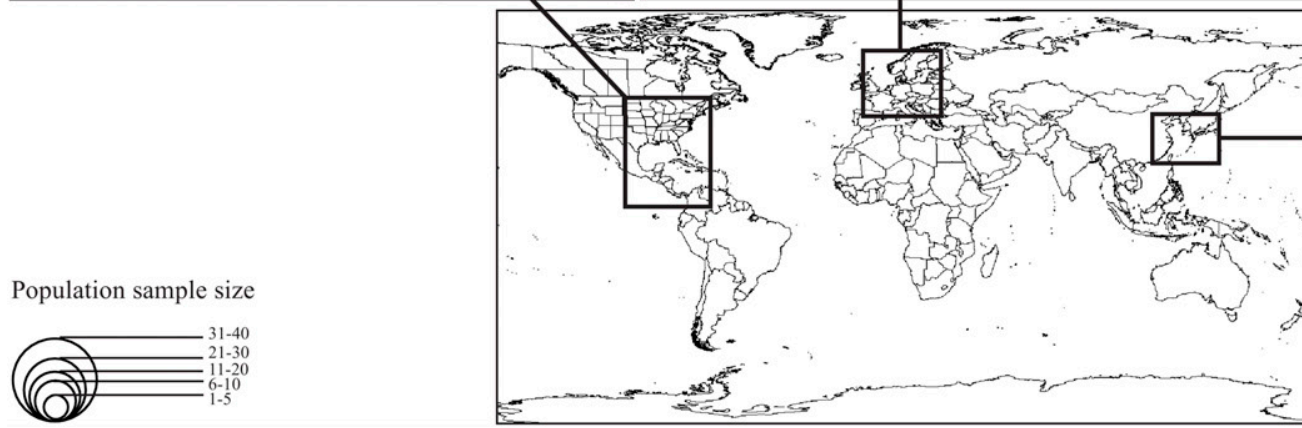

Fig. 1. Geographic representation of 14 elongation factor haplotypes of Lecanosticta acicola in America, Europe, and East Asia (enlarged areas). Numbers are the codes of locations corresponding to Table 1; each color represents one haplotype; size of circles represents number of isolates used in this study; scale bar indicate 500 and $1,000 \mathrm{~km}$ distance in each area. 
from 19 sequenced isolates. One of these haplotypes (GenBank accession no. KJ938451; designated in yellow in Fig. 1 and Supplementary Fig. S1; Fig. 2) was present in 14 isolates from Mississippi and all isolates from France, Spain, and Colombia. A single haplotype (KJ938438; designated in blue in Fig. 1; Fig. 2) was identified in all the isolates from five states in the northern United States $(n=27)$, Quebec in Canada $(n=7)$, and from nine countries in central and north Europe $(n=23)$. The three isolates from China, South Korea and Japan shared the same unique EF haplotype (KJ938450; designated as dark red in Fig. 1; Fig. 2).

Haplotype network revealed high level of diversity for isolates from Guatemala and Mexico. All haplotypes detected in Europe, Asia, Colombia, Canada, and the United States are closely related to those originating from Mexico.

The phylogenies generated with ML, BI, and MP analyses were congruent and are represented as a single MP tree with corresponding bootstrap support values for the nodes indicated on the branches (Fig. 2). For the BI analysis, the burn-in period was determined for the first 10,000 generations and all runs produced trees of the same log-likelihood.

In the phylogenies, two major clades were obtained. One clade included only the isolates originating from Mexico and Guatemala also revealing high diversity (Fig. 2). The isolates from Mexico and all of the isolates from Europe, North America, and Asia clustered together into one clade having high bootstrap support. Phylogenetic analyses suggested that the Mexican and Guatemalan clade is ancestral to the second clade (Fig. 2).

Microsatellite genotyping. All isolates were successfully amplified with the 11 microsatellite markers (Supplementary Table S2).

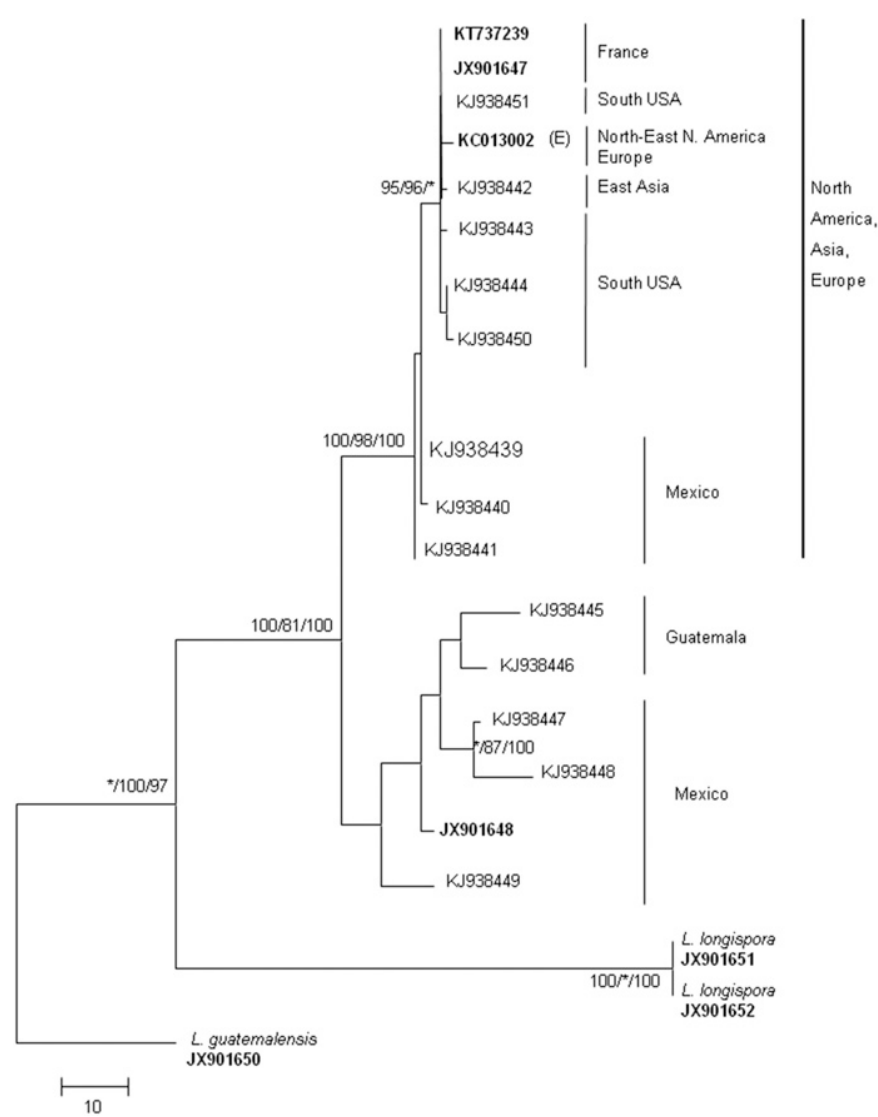

Fig. 2. Phylogram based on maximum parsimony analyses of elongation factor sequences. The representative isolates from GenBank are indicated in bold and the isolate indicated by (E) represents the epitype of Lecanosticta acicola. Maximum parsimony (MP), maximum likelihood (ML), and Bayesian inference (BI) bootstrap support values (1,000 replicates) are indicated at the nodes (support values: MP > 75\%; ML > 75\%; BI > 95\%; * indicates not significant). Scale bar indicates 10 nucleotide mutations.
The only exceptions were the isolates from Mexico and Guatemala that amplified with lower amplification success (80\%) despite several PCR optimization attempts. In addition, marker MD6 was monomorphic among all eight of these isolates. Isolates from Colombia and Asia were not included in some of the analyses due to small sample sizes in these populations.

Analyses of population structure. From 30 runs, STRUCTURE consistently identified two major groups $(K=2)$ for the 129 isolates analyzed. The first group included all the isolates from Mississippi (MS) and from southwest Europe (SE) and collectively is designated as the southern lineage. The second group, designated as the northern lineage, includes all the isolates from northeast of North America and those from central, southeastern, and northern Europe (Supplementary Fig. S2). At $\mathrm{K}=3$, the isolates from SE (France and Spain) separated out from the MS population in the southern lineage. $K=4$ and above revealed a collapse of genetic structure within the MS population. In the northern cluster, $33 \%$ of 30 runs at $K=5$ and $63 \%$ of 30 runs at $K=6$ distinguished a European (CE) group from a North American group (NA) cluster. Separate STRUCTURE analysis of the northern cluster at $\mathrm{K}=2$ confirmed the presence of these two distinct groups (Supplementary Fig. S3).

The PCA also identified two major groups across the whole data set, corresponding to those obtained with STRUCTURE at K = 2 . The SE population formed a cluster, distinct from the MS population (Fig. 3). When only the northern cluster obtained in STRUCTURE was analyzed using PCA, a faint distinction was evident between the European and the North American group (Fig. 3).

Genetic differentiation between pairs of STRUCTURE and PCAdefined clusters was highest between the populations from the southern lineage and those from the northern lineage $\left(\mathrm{F}_{\mathrm{ST}}=\right.$ 0.662-0.471; Table 2). Lower population genetic differentiation was seen between populations of the same lineage (MS versus SE: $\mathrm{F}_{\mathrm{ST}}=0.351$; NA versus CE: $\mathrm{F}_{\mathrm{ST}}=0.286$ ).

AMOVA based on $\varphi \mathrm{PT}$ value shows that only a low percentage (12.18\%) of molecular variance could be attributed to host species in Europe. Geographic origin of European isolates contributed to molecular variance only marginally (3.2\%) (Supplementary Table S3).

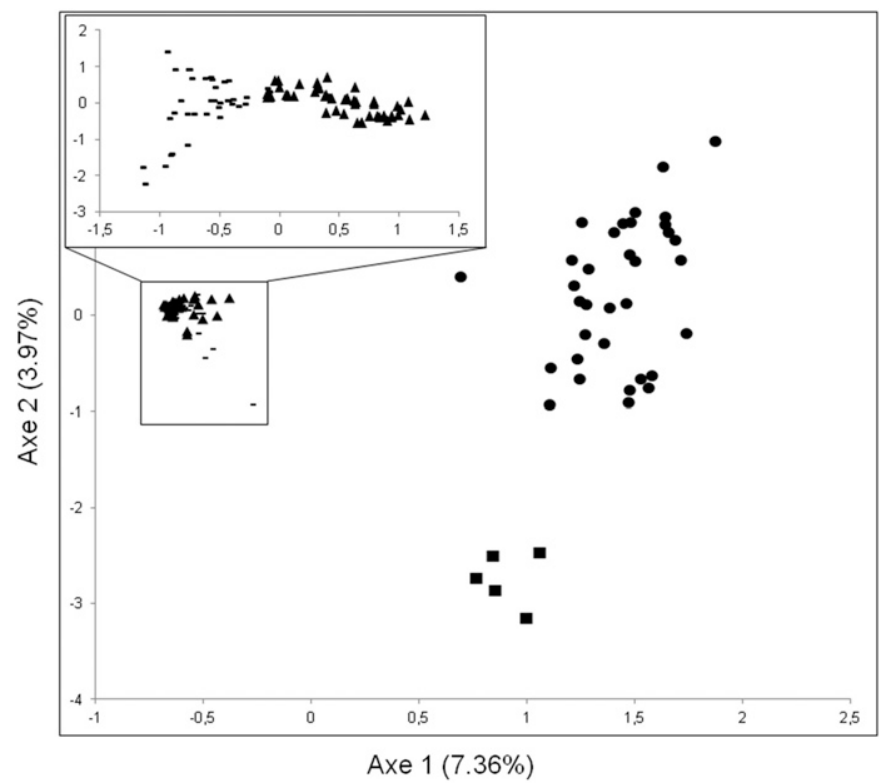

Fig. 3. Results of principal component analysis (PCA) analysis of the clonecorrected data of Lecanosticta acicola isolates represented on two principal component axes. The isolates originating from Mississippi are designated with a dot, isolates from southwest Europe by a square, isolates from northeastern North America (NA population) by a triangle and isolates representing CE population (central, northern, and southeastern Europe) are indicated with a dash. Results of separate PCA analysis of NA and CE (northern lineage) populations are presented in the nested rectangle (axe 1: $7.11 \%$; axe 2: 5.60\%). 
Genetic diversity in populations. A total of $43 \mathrm{MLHs}$ from 67 isolates were detected in the NA population from collections made in seven locations in northeastern North America $(\mathrm{CF}=0.358$; Table 3). The population from a single location in Mississippi contained 34 MLHs from 40 isolates analyzed $(C F=0.150)$. The population originating from two locations in southwest Europe consisted of nine isolates in which five MLHs were determined $(\mathrm{CF}=$ 0.444). The CE population, spanning 10 locations, was comprised of 69 isolates in which $48 \mathrm{MLHs}$ were obtained $(\mathrm{CF}=0.289$; Table 3).

The population from MS had the highest level of allelic richness $(7.1 \pm 0.89)$, highest number of alleles $(8.81)$, highest genotypic diversity (0.992), and highest genetic diversity $(0.46 \pm$ 0.32 ) of all the populations analyzed (Table 3 ). The NA population, representing isolates from a considerably larger area than the MS population, revealed a lower allelic richness $(1.59 \pm 0.21)$, number of alleles (3.55), genotypic diversity (0.955), and genetic diversity $(0.32 \pm 0.30)$. The $\mathrm{SE}$ population revealed the lowest values of the indices calculated (Table 3 ). The CE population had an allelic richness of $3.65 \pm 0.71,4.54$ number of alleles, a genotypic diversity of 0.931 , and a genetic diversity of $0.35 \pm 0.27$.

Migration scenarios. ABC analysis showed that the introduction of L. acicola into Europe was most likely from North America (scenario 6, relative posterior probability: 0.505; Figs. 4 and 5). This scenario assumed an unknown ancestral population that gave rise to the NA population. The MS population split from the NA and these two American populations gave rise to the two European populations, SE and CE, respectively. Scenarios assuming the opposite direction of migration, i.e., from Europe to North America, had the least support (relative posterior probability of scenario 2 and 3: $0.000,0.0087$; Fig. 4). Relative posterior probabilities were higher for scenarios assuming the presence of an ancestral population having given rise to one of the American populations (Fig. 4).

Posterior distributions of parameters for the best-supported scenarios are shown in Supplementary Table S4. Posterior distributions of effective population sizes for all sampled populations were relatively narrow and thus informative. The mode of the MS population was determined at 5,530, whereas it was 88 for the SE population. The mode of the NA population was identified at 829 and at 1,410 for the European CE population. The posterior distribution for the time of the split was determined as follows: divergence of CE from NA (t1c) occurred 127 generations ago, the divergence of SE from MS (t1h) occurred 654 generations ago, the divergence of $\mathrm{NA}+\mathrm{CE}$ populations from the MS + SE populations occurred probably 3,410 generations ago.

Power analyses revealed that the type I error (false positive) associated with the best- supported scenario (scenario 6) was relatively high (0.34). The mean of the type II errors (false negatives) associated with the best-supported scenario was low (0.078), indicating that the probability of selecting the best scenario

TABLE 3. Population characteristics based on microsatellite data and mating type idiomorphs for Lecanosticta acicola isolates from North America and Europe ${ }^{\mathrm{a}}$

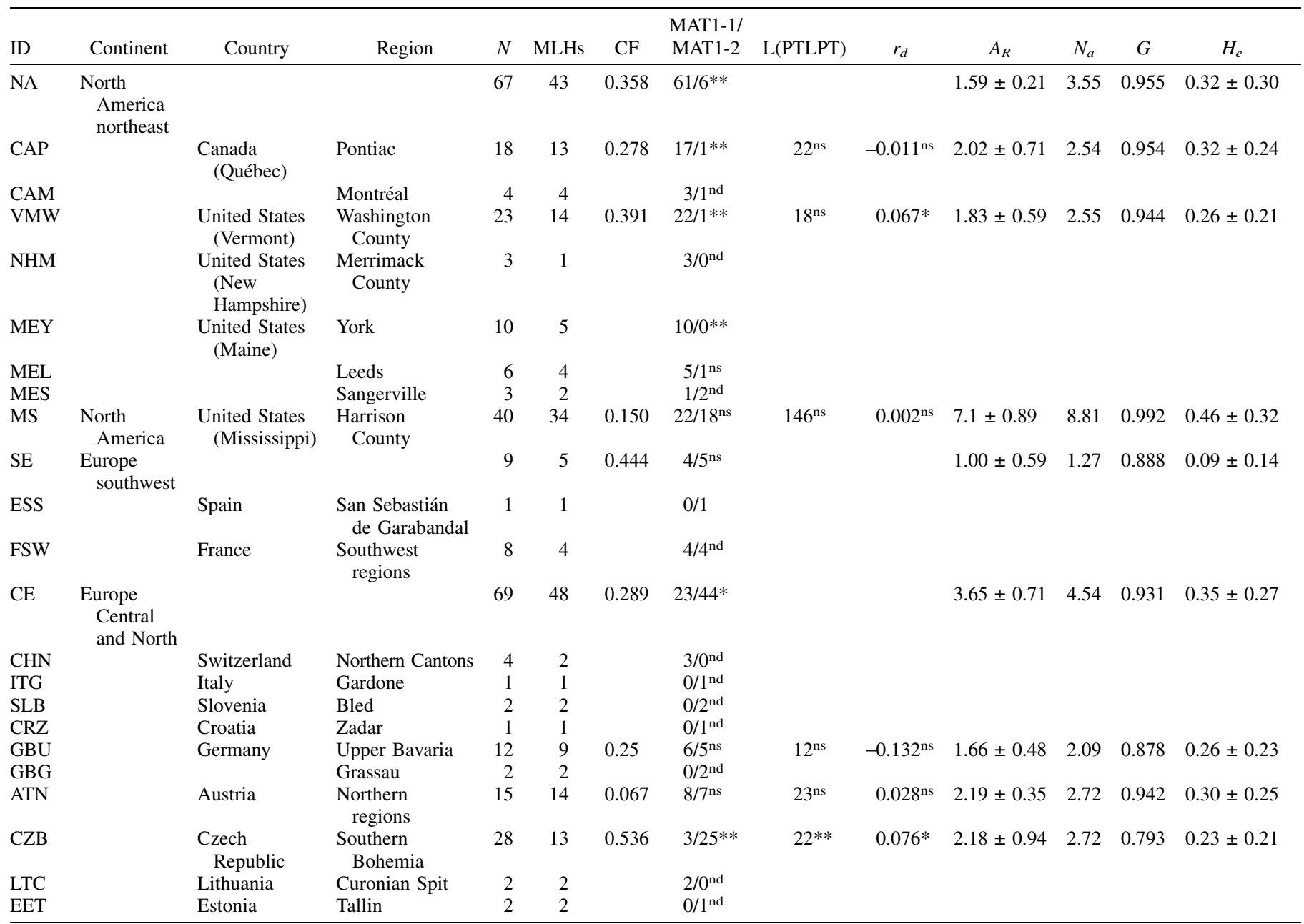

a $N$, number of isolates; MLHs, number of multilocus haplotypes; CF, clonal fraction; MAT1-1/MAT1-2 is the ratio of the mating type idiomorphs; the null hypothesis that the ratio is 1:1 was tested using exact binomial test; L(PTLPT) is the length of the observed tree in number of steps; $r B a r D$, multilocus linkage disequilibrium; for the L(PTLPT) and $r B a r D$ tests the null hypothesis of random mating was tested; nd, not determined; ns, not significant, $P>0.05$; $* P<0.05$; ** $P<0.001 ; N_{a}$, number of alleles; $A_{R}$, allelic richness averaged across loci \pm standard deviation); $G$, genotypic diversity; and $H_{e}$, gene diversity (mean \pm standard deviation) (Nei 1978). 
when the data were simulated with an alternative scenario, was low. Twenty-six summary statistics that had not been previously used for model selection were used for model checking. Only 1 of the 26 statistics had a low probability value when the model was checked (Supplementary Table S5), indicating that the selected scenario fitted the observed data well.
Reproductive mode. Frequency of the mating type idiomorphs for the isolates of L. acicola differed for different regions (Table 3 ). Both mating type idiomorphs were identified at equal ratios (MAT1-1/2: 4/4 in absolute counts) in Guatemala and Mexico. Similarly, the mating types did not differ significantly from a 1:1 ratio in the population from Mississippi but they did differ from this

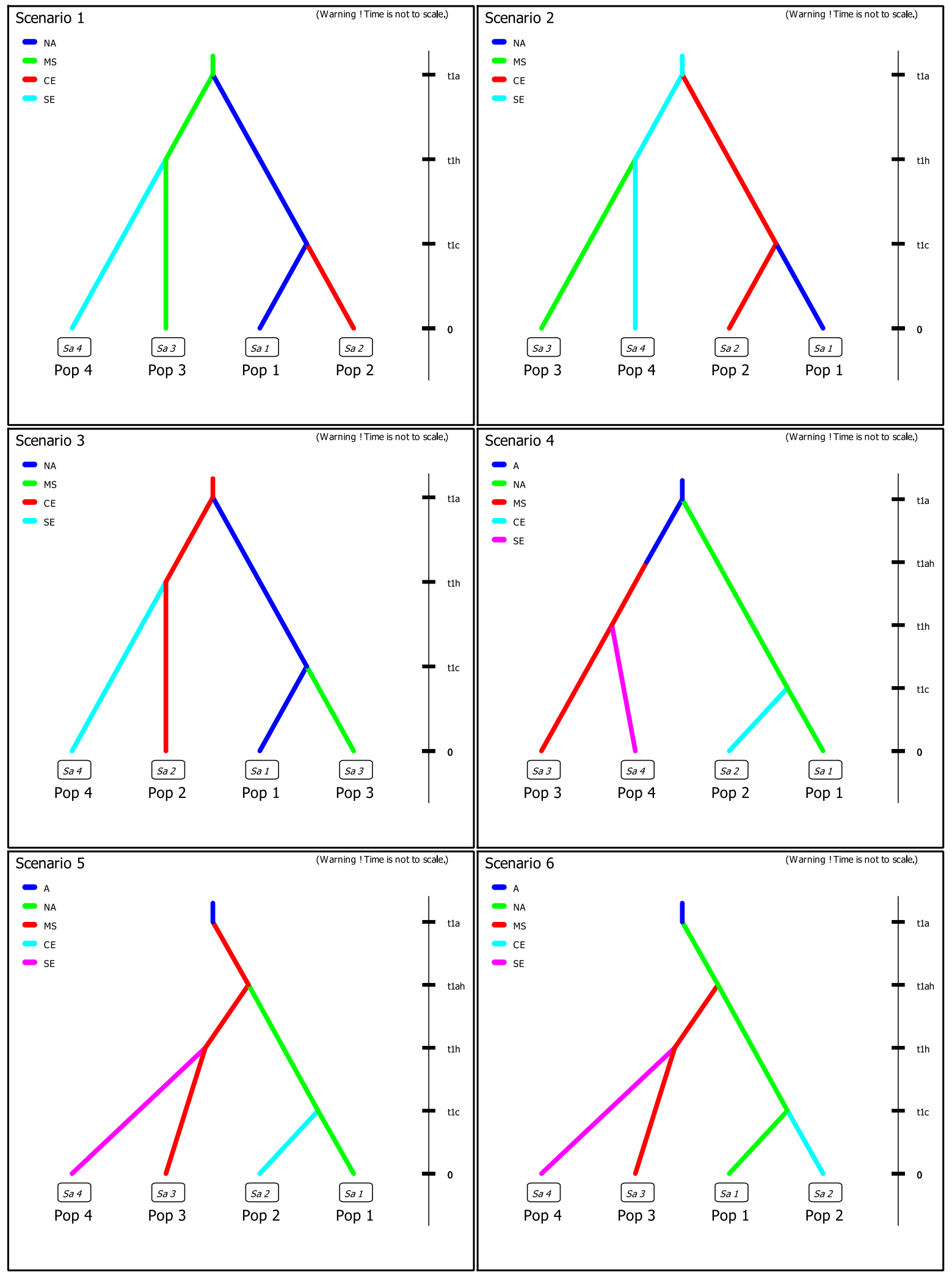

Fig. 4. Graphical representation of six scenarios of the demographic history and their relative posterior probabilities. Abbreviations used on time scales refer to time parameters used during simulations. Abbreviations of populations: A, assumed ancestral population; CE, central and northern European population; MS, Mississippi population; NA, northeastern North American population; and SE, southwestern European population. 
ratio for the NA population (Table 3). At a smaller geographical scale, isolates from CAP and VMW showed a similar skewed ratio for the MAT1-1/MAT1-2 at 17/1 and 22/1, respectively. Both mating type idiomorphs were found for isolates collected from the same needle originating from Canada. In Europe, the mating type ratio was 4/5 in SE and 23/44 in CE population (Table 3). For individual locations such as GBU (Germany) and ATN (Austria), the ratios did not significantly differ from 1:1. Only the MAT1-2 idiomorph was identified in isolates from the Czech Republic site Červená Blata (25 isolates), whereas only the MAT1-1 idiomorph was identified in isolates (three) collected in Borkovická Blata. Both mating type idiomorphs were found in isolates from a single needle collected in France. Only the MAT1-2 idiomorph was found in isolates from South America (Colombia; two isolates) and Asia (China, South Korea, and Japan; three isolates).

PTLPT revealed relatively long trees for the MS data set and did not significantly differ from randomized trees (Table 3 ). The isolates originating from two locations in the northeastern part of North America, CAP and VMH, had shorter tree lengths (22 and 18 steps, respectively), but they also did not differ significantly from randomized trees (Table 3). The same scenario was true for the isolates from two European locations (GBU, ATN) that produced relatively short trees at 12 and 23 steps, respectively (Table 3). In contrast, isolates from location CZB in the Czech Republic, produced a tree of 22 steps, which was significantly different from randomized trees (Table 3 ).

Another measure of random mating in the populations, $r$ BarD, did not reveal significant differences from a randomized data set (Table 3) in the MS population or in the isolates from CAP (Quebec, Canada). Measure of linkage disequilibrium was significantly different for the isolates from VMW (Vermont; Table 3). The three European locations showed consistent results with the PTLPT analyses: isolates from GBU (Germany) and ATN (Austria) were not significantly different from randomized data simulating a recombining population. $\mathrm{CZB}$ (Czech Republic) showed significant linkage disequilibrium and therefore, did not show any evidence for sexual recombination (Table 3 ).

\section{DISCUSSION}

This is the first investigation to consider the global movement of the pine needle pathogen L. acicola in different regions of the world. We detected high diversity among the isolates from Guatemala and Mexico and some of these most likely represent cryptic species closely related to, but distinct from, L. acicola. The isolates from East Asia formed a unique and discrete group. Furthermore, two distinct populations in North America (southern and northern one) were identified and both populations have very likely been introduced into Europe independently. Interestingly, these two European populations of L. acicola reflect the geographic distribution of North-American populations, which are probably related to climatic and host adaption for each of the lineages. In addition, evidence was provided for sexual recombination within the pathogen populations in parts of Europe and in North American. It was thus clear that L. acicola is an invasive alien in Europe that reproduces asexually and very likely also sexually.

Phylogenetic relationships within L. acicola, population structure, and genetic diversity. Haplotype and nucleotide diversity, determined from the EF sequences, revealed high diversity among the isolates from Guatemala and Mexico. These results are consistent with the view of Evans (Evans 1984), who attributed substantial morphological variation to the existence of a species complex in L. acicola. The high level of genetic diversity for L. acicola in this region could be attributed to its long-term or native presence in Central America and Mexico, where it occurs from sea-level tropical forests to high altitude rain forests (Evans 1984). The pathogen is omnipresent on native pines but it was occasionally also found to cause a serious needle blight (Evans 1984; I. Barnes, unpublished data). This suggests a high level of host resistance, probably as a result of long-term plant-pathogen coevolution (Barrett et al. 2008). High diversity among the isolates originating from Mexico is probably also related to the high diversity of pine species found in Mexico that is also the highest at global scale (Farjon 1996; Gernandt and Pérez-de la Rosa 2014).

The fact that the microsatellite markers, designed from isolates from the United States, Europe, and Japan, amplified poorly in the Central American isolates adds credence to the view that L. acicola represents a species complex in Central America and Mexico. Phylogenetic analyses indicated that the Central American and Mexican haplotypes of L. acicola are ancestral to those found elsewhere in the world. Phylogenetic analyses indicated that

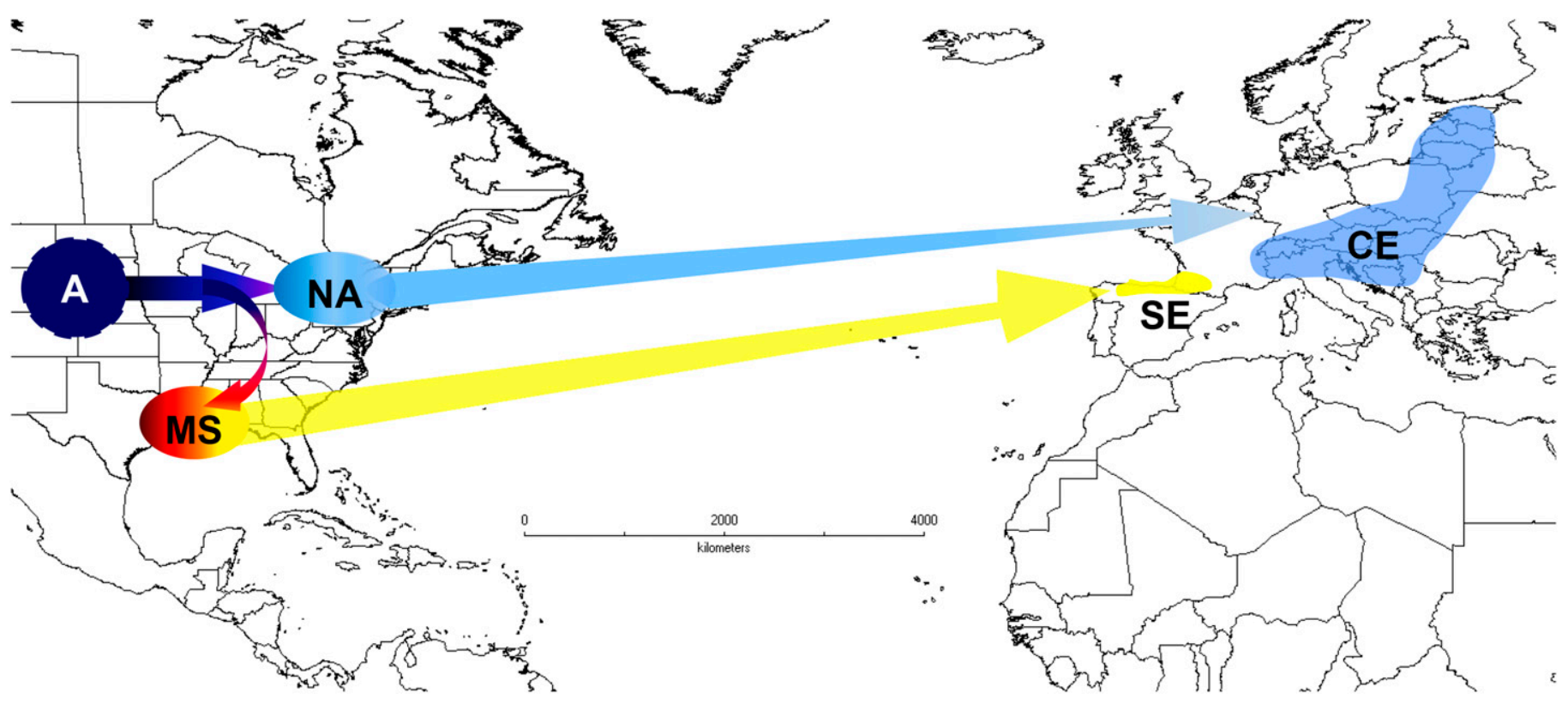

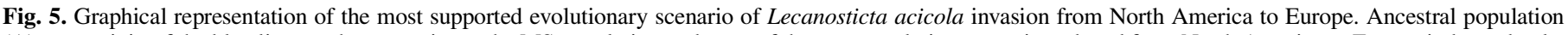

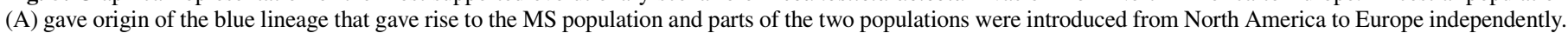

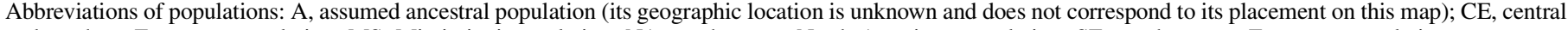
and northern European population; MS, Mississippi population; NA, northeastern North American population; SE, southwestern European population. 
Mexico is probably the area of origin of L. acicola populations in the United States and Canada.

Haplotypic and nucleotide diversity for isolates of $L$. acicola from North America was lower than that found in Mexico and Guatemala. This corresponds to a more uniform conidial morphology observed by Evans (1984) in collections from North America. The population from Mississippi encompassed the highest genetic diversity and allelic richness of all populations analyzed. Two distinct lineages (southern and a northern lineage) reported by Huang et al. (1995) from their RAPD data, were also observed in this study using both EF sequence data and microsatellite markers. These two lineages have been reported to differ in culture morphology, conidial germination, and pathogenicity to various pine species (Huang et al. 1995; Kais 1972). All these findings suggest a level of adaption to climatic conditions and host for isolates in the two lineages, a view also proposed by Huang et al. (1995). These two lineages could represent two distinct but cryptic species (Restrepo et al. 2014). This is likely given the fact that many cryptic species are being discovered in ascomycete fungi where DNA sequence data (Sakalidis et al. 2013; Walker et al. 2011) or microsatellite markers (Pérez et al. 2012; Schoebel et al. 2013) are applied to taxonomic and population genetic studies.

The same two lineages of L. acicola present in North America were also found in collections of isolates from Europe and they had similar geographical distributions. The southern lineage was identified in Spain and France, and the northern lineage in several other parts of Europe. Their distinct geographical distribution is very likely not associated with pine species but could be explained by their different climatic requirements (especially to temperature). The presence of the more virulent (Kais 1972) southern lineage in France could explain a serious outbreak of brown spot needle blight in the 1990s (Lévy and Lafaurie 1994). This epidemic resulted in the total loss of about 270 ha of $P$. attenuata $\times$ radiata plantations (Lévy 1996). It is also interesting, that in both North America and Europe, neither the southern or northern lineages have overlapping geographical distributions.

The southern lineage of L. acicola was identified in Colombia where the pathogen has caused severe defoliation in pine plantations in the past (Evans 1984). Pines are not native in South America and it is highly likely that L. acicola was introduced into this area with plant material. A similar human-mediated introduction has been documented for the related pine needle pathogen, Dothistroma septosporum, from Chile into Ecuador (Barnes et al. 2014). However, in order to determine the origin of L. acicola in Colombia, additional investigations will be required.

The L. acicola lineage identified in East Asia was unique and found only in this region. Its introduction was suggested to have occurred from the southern or southeastern United States (Huang et al. 1995). The present study shows clearly that the isolates sampled in East Asia do not form part of the same southern lineage that is present in the southern United States or Europe. However, the introduction of L. acicola into Asia from an unsampled population in the southeastern United States cannot be ruled out because only isolates from Mississippi were considered in this study.

Evolutionary relationships between North American and European populations. Analyses of demographic history revealed that both North American lineages of L. acicola were most likely introduced into Europe independently after the divergence of the southern and northern lineages in North America. This pattern of multiple introductions from different sources seems to be common for worldwide invasive species as has been documented for various organisms using ABC approaches (Barrès et al. 2012; Konečný et al. 2013). Historically (based on ABC analyses), the southern lineage was introduced into Europe first, followed by the northern lineage. This is, however, difficult to verify because there could be many interfering parameters including differing mean generation times in each lineage that could be influenced by climatic conditions. The time at which the southern lineage split from northern lineage was estimated to have been about 3,400 generations ago. Although this is an estimated value, it shows that the divergence of these lineages is relatively ancient. If we consider life cycle of 1 year, this would correspond to a period of approximately 3,400 years ago. Although it is clear that the European isolates of L. acicola originated in North America, determination of the exact origin of these isolates would require more intensive and precise sampling in North America as well as in other parts of the world.

Reproductive mode. Both mating type idiomorphs were identified in the isolates of L. acicola originating from Mexico and Guatemala. This confirms that the fungus is heterothallic and that it probably undergoes sexual reproduction. This would be consistent with EF sequence data and with the fact that Evans (1984) observed sexual structures in Lecanosticta spp. from Central America.

Mating type idiomorph distribution and microsatellite data analyses provided strong indication that the population of L. acicola from Mississippi is undergoing sexual reproduction. This result was expected, because sexual structures of the fungi were commonly found on infected needles in the southeastern United States (Kais 1971; Siggers 1944) and ascospores have been detected throughout the whole year (Henry 1954). Results of this study also indicated that random mating occurs in the population from northeastern North America. Moreover, the presence of both mating type idiomorphs in isolates from the same needle in Canada would clearly increase opportunities for individuals of opposite mating type to interact and reproduce sexually (Barnes et al. 2011; Linde et al. 2003). Neither asci, nor ascospores have, however, been observed in the northern regions of North America (Evans 1984; Nicholls and Hudler 1972). Although windblown ascospores would be formed only occasionally in this population, they could play an important role in causing rapid outbreaks of $L$. acicola, such as those recently been observed in the northeastern United States (Munck et al. 2012). Mating type idiomorph frequencies as well as microsatellite data analyses suggest that sexual reproduction is most likely occurring in L. acicola in Austria and Germany. In contrast, data obtained from the isolates from the Czech Republic showed that the pathogen reproduces predominantly asexually.

This study provides the first indication for sexual reproduction of L. acicola in Europe. Sexual reproduction, which gives rise to windborne ascospores, could explain the current epidemics of brown spot needle blight in Switzerland, Germany and Austria (Angst 2011; Blaschke 2002; Hintsteiner et al. 2012). Ascospore dissemination thus probably plays a major role in the long distance dispersal of L. acicola within Europe (Wingen et al. 2013) as has also been seen for the wheat pathogen Phaeosphaeria nodorum (Sommerhalder et al. 2010). Sexual reproduction allows for the formation of new haplotypes, while asexual reproduction can enhance fast multiplication of advantageous haplotypes. This could lead to local adaptation (Milgroom 1996) of L. acicola.

Conclusions. We have shown that at least two introductions of L. acicola have occurred from North America into Europe in the past. This is another example of an intercontinental introduction of a plant pathogen into a new environment, most likely as a consequence of human activity. In addition, results showed that L. acicola most probably also reproduces sexually. The pathogen therefore has a substantial potential to adapt to new environments and infect new pine host species. Its presence in geographical areas with variable climates illustrates its high level of ecological tolerance and ability to adapt to new environments. It can thus be expected that L. acicola will spread rapidly from infected trees to surrounding pine stands if climatic conditions were to become favorable for infection to occur. L. acicola is a serious pathogen and it remains on the European A2 list of quarantine pathogens. It is, therefore, important to monitor its spread and movement in the 
future, including impact of a potential contact between isolates of the two lineages in Europe.

\section{ACKNOWLEDGMENTS}

We thank our colleagues listed in Supplementary Table S1 for providing needle samples or fungal isolates without which this study would not have been possible; and S. Krumböck, D. Palovčíková, L. Innes, D. Nelson, M. Kostovčík, C. Bertheau, H. Schuller, and M. Kloudová for their contribution to this study. The project was supported financially by COST CZ LD12031 (DIAROD), the FPS COST Action FP1102 (DIAROD), Project indicators of trees vitality Reg. No. CZ.1.07/2.3.00/20.0265 co-financed by the European Social Fund and the state budget of the Czech Republic, the Scholarship Foundation of the Republic of Austria (OeAD-GmbH, Austria) for J. Janoušek. The research was supported with funding from the Austrian Science Fund FWF and the European Union Seventh Framework Programme FP7 2007-2013 (KBBE 2009-3) under grant agreement 245268 ISEFOR. Access to computing and storage facilities owned by parties and projects contributing to the National Grid Infrastructure MetaCentrum, provided under the programme "Projects of Large Infrastructure for Research, Development, and Innovations" (LM2010005), is greatly appreciated.

\section{LITERATURE CITED}

Agapow, P.-M., and Burt, A. 2001. Indices of multilocus linkage disequilibrium. Mol. Ecol. Notes 1:101-102.

Alonso, M. R., and Perez, P. 1987. Asociacion Lecanosticta acicola, Lophodermium australe y Pestalozzia sp. sobre Pinus spp. en Cuba. Rev. For. Baracoa 17:99-103.

Angst, A. 2011. Braune Föhren in Garten und Parks. Wald Holz 4:41-42.

Bandelt, H.-J., Forster, P., and Röhl, A. 1999. Median-joining networks for inferring intraspecific phylogenies. Mol. Biol. Evol. 16:37-48.

Barnes, I., Crous, P. W., Wingfield, B., and Wingfield, M. J. 2004. Multigene phylogenies reveal that red band needle blight of Pinus is caused by two distinct species of Dothistroma, D. septosporum and D. pini. Stud. Mycol. 50:551-565.

Barnes, I., Kirisits, T., Wingfield, M. J., and Wingfield, B. D. 2011. Needle blight of pine caused by two species of Dothistroma in Hungary. For. Pathol. 41:361-369.

Barnes, I., Wingfield, M. J., Carbone, I., Kirisits, T., and Wingfield, B. D. 2014. Population structure and diversity of an invasive pine needle pathogen reflects anthropogenic activity. Ecol. Evol. 4:3642-3661.

Barrès, B., Carlier, J., Seguin, M., Fenouillet, C., Cilas, C., and Ravigné, V. 2012. Understanding the recent colonization history of a plant pathogenic fungus using population genetic tools and Approximate Bayesian Computation. Heredity 109:269-279.

Barrett, L. G., Thrall, P. H., Burdon, J. J., and Linde, C. C. 2008. Life history determines genetic structure and evolutionary potential of host-parasite interactions. Trends Ecol. Evol. 23:678-685.

Bazin, É., Mathé-Hubert, H., Facon, B., Carlier, J., and Ravigné, V. 2014. The effect of mating system on invasiveness: Some genetic load may be advantageous when invading new environments. Biol. Invasions 16:875-886.

Beaumont, M. A., Nielsen, R., Robert, C., Hey, J., Gaggiotti, O., Knowles, L., and Estoup, A. 2010. In defence of model-based inference in phylogeography. Mol. Ecol. 19:436-446.

Beaumont, M. A., Zhang, W., and Balding, D. J. 2002. Approximate Bayesian computation in population genetics. Genetics 162:2025-2035.

Belkhir, K., Borsa, P., Chikhi, L., Raufaste, N., and Bonhomme, F. 1996-2004. GENETIX 4.05, logiciel sous Windows TM pour la génétique des populations. Laboratoire Génome, Populations, Interactions, Université de Montpellier II, Montpellier, France.

Bertorelle, G., Benazzo, A., and Mona, S. 2010. ABC as a flexible framework to estimate demography over space and time: Some cons, many pros. Mol. Ecol. 19:2609-2625.

Blaschke, M. 2002. Die Nadeln der Latsche (Pinus mugo), ein Habitat fur zwei Pilzarten der Gattung Mycosphaerella. Mycol. Bavarica 5:56-60.

Boissin, E., Hurley, B., Wingfield, M. J., Vasaitis, R., Stenlid, J., Davis, C., de Groot, P., Ahumada, R., Carnegie, A., Goldarazena, A., Klasmer, P., Wermelinger, B., and Slippers, B. 2012. Retracing the routes of introduction of invasive species: The case of the Sirex noctilio woodwasp. Mol. Ecol. 21: 5728-5744.

Boyce, J. S. 1959. Brown spot needle blight on eastern white pine. Plant Dis. Rep. 43:420.

Boyd, I. L., Freer-Smith, P. H., Gilligan, C. A., and Godfray, H. C. 2013. The consequence of tree pests and diseases for ecosystem services. Science 342: 1235773.
Burt, A., Carter, D. A., Koenig, G., White, T. J., and Taylor, J. W. 1996. Molecular markers reveal cryptic sex in the human pathogen Coccidioides immitis. Proc. Natl. Acad. Sci. USA 93:770-773.

Clement, M., Posada, D., and Crandall, K. A. 2000. TCS: A computer program to estimate gene genealogies. Mol. Ecol. 9:1657-1659.

Cornuet, J. M., Pudlo, P., Veyssier, J., Dehne-Garcia, A., Gautier, M., Leblois, R., Marin, J. M., and Estoup, A. 2014. DIYABC v2.0: A software to make approximate Bayesian computation inferences about population history using single nucleotide polymorphism, DNA sequence and microsatellite data. Bioinformatics 30:1187-1189.

Cornuet, J. M., Ravigné, V., and Estoup, A. 2010. Inference on population history and model checking using DNA sequence and microsatellite data with the software DIYABC (v1.0). BMC Bioinformatics 11:401.

Darriba, D., Taboada, G., Doallo, R., and Posada, D. 2012. jModelTest 2: More models, new heuristics and parallel computing. Nat. Methods 9:772.

Desprez-Loustau, M. L., Robin, C., Buée, M., Courtecuisse, R., Garbaye, J., Suffert, F., Sache, I., and Rizzo, D. M. 2007. The fungal dimension of biological invasions. Trends Ecol. Evol. 22:472-480.

Dilmaghani, A., Gladieux, P., Gout, L., Giraud, T., Brunner, P. C., Stachowiak, A., Balesdent, M. H., and Rouxel, T. 2012. Migration patterns and changes in population biology associated with the worldwide spread of the oilseed rape pathogen Leptosphaeria maculans. Mol. Ecol. 21:2519-2533.

Dutech, C., Barrès, B., Bridier, J., Robin, C., Milgroom, M. G., and Ravigné, V. 2012. The chestnut blight fungus world tour: Successive introduction events from diverse origins in an invasive plant fungal pathogen. Mol. Ecol. 21:3931-3946.

Earl, D. A., and vonHoldt, B. M. 2012. STRUCTURE HARVESTER: A website and program for visualizing STRUCTURE output and implementing the Evanno method. Conserv. Genet. Resour. 4:359-361.

Estoup, A., Jarne, P., and Cornuet, J. M. 2002. Homoplasy and mutation model at microsatellite loci and their consequences for population genetics analysis. Mol. Ecol. 11:1591-1604.

Estoup, A., Lombaert, E., Marin, J. M., Guillemaud, T., Pudlo, P., Robert, C. P., and Cornuet, J. M. 2012. Estimation of demo-genetic model probabilities with approximate Bayesian computation using linear discriminant analysis on summary statistics. Mol. Ecol. Resour. 12:846-855.

Evans, H. C. 1984. The genus Mycosphaerella and its anamorphs. Mycol. Pap. 153:1-103.

Excoffier, L., and Heckel, G. 2006. Computer programs for population genetics data analysis: A survival guide. Nat. Rev. Genet. 7:745-758.

Excoffier, L., Smouse, P. E., and Quattro, J. M. 1992. Analysis of molecular variance inferred from metric distances among DNA haplotypes: Application to human mitochondrial DNA restriction data. Genetics 131:479-491.

Eyre, C. A., and Garbelotto, M. 2015. Detection, diversity, and population dynamics of waterborne Phytophthora ramorum populations. Phytopathology 105:57-68.

Falush, D., Stephens, M., and Pritchard, J. K. 2003. Inference of population structure using multilocus genotype data: Linked loci and correlated allele frequencies. Genetics 164:1567-1587.

Farjon, A. F. L. S. 1996. Biodiversity of Pinus (Pinaceae) in Mexico: Speciation and paleo-endemism. Bot. J. Linn. Soc. 121:365-384.

Felsenstein, J. 1985. Confidence limits of phylogenies: An approach using the bootstrap. Evolution 39:783-791.

Fisher, M. C., Henk, D. A., Briggs, C. J., Brownstein, J. S., Madoff, L. C., McCraw, S. L., and Gurr, S. J. 2012. Emerging fungal threats to animal, plant and ecosystem health. Nature 484:186-194.

Garbelotto, M. 2008. Molecular analysis to study invasions by forest pathogens. Phytopathol. Mediterr. 47:183-203.

Gernandt, D. S., and Pérez-de la Rosa, J. A. 2014. Biodiversidad de Pinophyta (coníferas) en México. Rev. Mex. Biodiversidad 85:126-133.

Gibson, I. A. S. 1980. Two pine needle fungi new to Colombia. Trop. Pest Manage. 26:38-40.

Giraud, T., Enjalbert, J., Fournier, E., Delmotte, F., and Dutech, C. 2008. Population genetics of fungal diseases of plants. Parasite 15:449-454.

Goudet, J. 2002. FSTAT, a programme to estimate and test gene diversities and fixation indices (version 2.9.3). http://www2.unil.ch/popgen/softwares/fstat. htm

Gross, A., Hosoya, T., and Queloz, V. 2014. Population structure of the invasive forest pathogen Hymenoscyphus pseudoalbidus. Mol. Ecol. 23:2943-2960.

Grünwald, N. J., and Goss, E. M. 2011. Evolution and population genetics of exotic and re-emerging pathogens: Novel tools and approaches. Annu. Rev. Phytopathol. 49:249-267.

Guillemaud, T., Beaumont, M. A., Ciosi, M., Cornuet, J. M., and Estoup, A. 2010. Inferring introduction routes of invasive species using approximate Bayesian computation on microsatellite data. Heredity 104:88-99.

Guindon, S., Dufayard, J. F., Lefort, V., Anisimova, M., Hordijk, W., and Gascuel, O. 2010. New algorithms and methods to estimate maximumlikelihood phylogenies: Assessing the performance of PhyML 3.0. Syst. Biol. 59:307-321. 
Guindon, S., and Gascuel, O. 2003. A simple, fast, and accurate algorithm to estimate large phylogenies by maximum likelihood. Syst. Biol. 52:696-704.

Hall, T. A. 1999. BioEdit: A user-friendly biological sequence alignment editor and analysis program for Windows 95/98/NT. Nucleic Acids Symp. Ser. 41:95-98.

Henry, B. W. 1954. Sporulation by the brown spot fungus on longleaf pine needles. Phytopathology 44:385-386.

Hintsteiner, M., Cech, T. L., Halmschlager, E., Stauffer, C., Kirisits, T., and Sieber, T. 2012. First report of Mycosphaerella dearnessii on Pinus nigra var. nigra in Austria. For. Pathol. 42:437-440.

Huang, Z.-Y., Smalley, E. B., and Guries, R. P. 1995. Differentiation of Mycosphaerella dearnessii by cultural characters and RAPD analysis. Phytopathology 85:522-527.

Hubisz, M. J., Falush, D., Stephens, M., and Pritchard, J. K. 2009. Inferring weak population structure with the assistance of sample group information. Mol. Ecol. Resour. 9:1322-1332.

Ioos, R., Fabre, B., Saurat, C., Fourrier, C., Frey, P., and Marçais, B. 2010. Development, comparison, and validation of real-time and conventional PCR tools for the detection of the fungal pathogens causing brown spot and red band needle blights of pine. Phytopathology 100:105-114.

Jacobs, K., Bergdahl, D. R., Wingfield, M. J., Halik, S., Seifert, K. A., Bright, D. E., and Wingfield, B. D. 2004. Leptographium wingfieldii introduced into North America and found associated with exotic Tomicus piniperda and native bark beetles. Mycol. Res. 108:411-418.

Jakobsson, M., and Rosenberg, N. A. 2007. CLUMPP: A cluster matching and permutation program for dealing with label switching and multimodality in analysis of population structure. Bioinformatics 23:1801-1806.

Jankovský, L., Palovčíková, D., and Tomšovský, M. 2009. Brown spot needle blight associated with Mycosphaerella dearnessii occurs on Pinus rotundata in the Czech Republic. Plant Pathol. 58:398.

Janoušek, J., Krumböck, S., Kirisits, T., Bradshaw, R. E., Barnes, I., Jankovský, L., and Stauffer, C. 2014. Development of microsatellite and mating type markers for the pine needle pathogen Lecanosticta acicola. Australas. Plant Pathol. 43:161-165.

Jombart, T., Pontier, D., and Dufour, A. B. 2009. Genetic markers in the playground of multivariate analysis. Heredity 102:330-341.

Kais, A. G. 1971. Dispersal of Scirrhia acicola spores in southern Mississippi. Plant Dis. Rep. 55:309-311.

Kais, A. G. 1972. Variation between southern and northern isolates of Scirrhia acicola. Phytopathology 62:768.

Kais, A. G. 1975. Environmental factors affecting brown-spot infection on longleaf pine. Phytopathology 65:1389-1392.

Katoh, K., Misawa, K., Kuma, K., and Miyata, T. 2002. MAFFT: A novel method for rapid multiple sequence alignment based on fast Fourier transform. Nucleic Acids Res. 30:3059-3066.

Katoh, K., and Standley, D. M. 2013. MAFFT multiple sequence alignment software version 7: Improvements in performance and usability. Mol. Biol. Evol. 30:772-780.

Konečný, A., Estoup, A., Duplantier, J. M., Bryja, J., Bâ, K., Galan, M., Tatard, C., and Cosson, J. F. 2013. Invasion genetics of the introduced black rat (Rattus rattus) in Senegal, West Africa. Mol. Ecol. 22:286-300.

Laflamme, G., Côté, C., and Innes, L. 2010. White pine needle diseases in Eastern Canada. (Abstr.) Phytopathology 101(suppl.):S260.

Lévy, A. 1996. Le point sur le champignon de quarantine Scirrhia acicola dans le sud-ouest de la France. La Santé des Forêts 28-30.

Lévy, A., and Lafaurie, C. 1994. Découverte de Scirrhia acicola. Phytoma-La défense des végétaux 463:33-35.

Librado, P., and Rozas, J. 2009. DnaSP v5: A software for comprehensive analysis of DNA polymorphism data. Bioinformatics 25:1451-1452.

Linde, C. C., Zala, M., Ceccarelli, S., and McDonald, B. A. 2003. Further evidence for sexual reproduction in Rhynchosporium secalis based on distribution and frequency of mating-type alleles. Fungal Genet. Biol. 40:115-125.

Martínez, J. B. 1942. Las micosis del Pinus insignis en Guipuzcoa. Publ. Inst. Invest. Exp. 13(23).

McDonald, B. A., and Linde, C. 2002. Pathogen population genetics, evolutionary potential, and durable resistance. Annu. Rev. Phytopathol. 40: 349-379.

McDonald, J. H. 2009. Handbook of Biological Statistics. Sparky House Publishing, Baltimore, MD.

McVean, G. 2009. A genealogical interpretation of principal components analysis. PLoS Genet. 5:e1000686.

Milatović, I. 1976. Needle cast of pines caused by fungi Scirrhia pini Funk et Parker and S. acicola (Dearn.) Siggers in Yugoslavia. Poljopr. Znan. Smotra 39:511-513.

Milgroom, M. G. 1996. Recombination and the multilocus structure of fungal populations. Annu. Rev. Phytopathol. 34:457-477.

Munck, I. A., Burns, B., Lombard, K., Weimer, J., and Ostrofsky, W. D. 2012. What is causing white pine needle damage in northeastern North America? (Abstr.) Phytopathology 102(suppl.):S4.84.
Nei, M. 1978. Estimation of average heterozygosity and genetic distance from a small number of individuals. Genetics 89:583-590.

Nicholls, T. H., and Hudler, G. W. 1972. Red pine-A new host for brown spot (Scirrhia acicola). Plant Dis. Rep. 56:712-713.

Peakall, R., and Smouse, P. E. 2006. GENALEX 6: Genetic analysis in Excel. Population genetic software for teaching and research. Mol. Ecol. Notes 6: 288-295.

Peakall, R., and Smouse, P. E. 2012. GenAlEx 6.5: Genetic analysis in Excel. Population genetic software for teaching and research-An update. Bioinformatics 28:2537-2539.

Pehl, L., Cech, T. L., and Ioos, R. 2015. PM 7/46 (3) Lecanosticta acicola (formerly Mycosphaerella dearnessii), Dothistroma septosporum (formerly Mycosphaerella pini) and Dothistroma pini. EPPO Bull. 45:163-182.

Pérez, G., Slippers, B., Wingfield, M. J., Wingfield, B. D., Carnegie, A. J., and Burgess, T. I. 2012. Cryptic species, native populations and biological invasions by a eucalypt forest pathogen. Mol. Ecol. 21:4452-4471.

Pritchard, J. K., Stephens, M., and Donelly, P. 2000. Inference of population structure using multilocus genotype data. Genetics 155:945-959.

Quaedvlieg, W., Groenewald, J. Z., Yáñez-Morales, M., De, J., and Crous, P. W. 2012. DNA barcoding of Mycosphaerella species of quarantine importance to Europe. Persoonia 29:101-115.

Rambaut, A., and Drummond, A. 2007. Tracer v. 1.5. Computer program and documentation distributed by the authors. http://beast.bio.ed.ac.uk/Tracer

Restrepo, S., Tabima, J. F., Mideros, M. F., Grünwald, N. J., and Matute, D. R. 2014. Speciation in fungal and oomycete plant pathogens. Annu. Rev. Phytopathol. 52:289-316.

Ronquist, F., and Huelsenbeck, J. P. 2003. MrBayes 3: Bayesian phylogenetic inference under mixed models. Bioinformatics 19:1572-1574.

Rosenberg, N. A. 2004. DISTRUCT: A program for the graphical display of population structure. Mol. Ecol. Notes 4:137-138.

Sakalidis, M. L., Slippers, B., Wingfield, B. D., Hardy, G. E. S. J., Burgess, T. I., and Austin, J. 2013. The challenge of understanding the origin, pathways and extent of fungal invasions: Global populations of the Neofusicoccum parvum-N. ribis species complex. Divers. Distrib. 19: 873-883.

Saleh, D., Xu, P., Shen, Y., Li, C., Adreit, H., Milazzo, J., Ravigné, V., Bazin, É., Notteghem, J. L., Fournier, E., and Tharreau, D. 2012. Sex at the origin: An Asian population of the rice blast fungus Magnaporthe oryzae reproduces sexually. Mol. Ecol. 21:1330-1344.

Santini, A., Ghelardini, L., De Pace, C., Desprez-Loustau, M. L., Capretti, P., Chandelier, A., Cech, T., Chira, D., Diamandis, S., Gaitniekis, T., Hantula, J., Holdenrieder, O., Jankovský, L., Jung, T., Jurc, D., Kirisits, T., Kunca, A., Lygis, V., Malecka, M., Marçais, B., Schmitz, S., Schumacher, J., Solheim, H., Solla, A., Szabo, I., Tsopelas, P., Vannini, A., Vettraino, A. M., Webber, J., Woodward, S., and Stenlid, J. 2013. Biogeographical patterns and determinants of invasion by forest pathogens in Europe. New Phytol. 197:238-250.

Schoebel, C. N., Jung, E., and Prospero, S. 2013. Development of new polymorphic microsatellite markers for three closely related plant-pathogenic Phytophthora species using 454-pyrosequencing and their potential applications. Phytopathology 103:1020-1027.

Siggers, P. V. 1944. The brown spot needle blight of pine seedlings. Pages 1-36 in: Tech. Bull. No. 870.

Sinclair, W., and Lyon, H. H. 2005. Diseases of Trees and Shrubs, 2nd Ed. Cornell University Press, Ithaca, NY.

Sommerhalder, R. J., McDonald, B. A., Mascher, F., and Zhan, J. 2010. Sexual recombinants make a significant contribution to epidemics caused by the wheat pathogen Phaeosphaeria nodorum. Phytopathology 100:855-862.

Stanosz, G. 1990. Premature needle drop and symptoms associated with brown spot needle blight on Pinus strobus in Northcentral Pennsylvania. Phytopathology 80:124

Sunnåker, M., Busetto, A. G., Numminen, E., Corander, J., Foll, M., and Dessimoz, C. 2013. Approximate Bayesian computation. PLOS Comput. Biol. 9:e1002803

Swofford, D. L. 2003. PAUP*. Phylogenetic Analysis Using Parsimony (*and Other Methods). Version 4. Sinauer Associates, Sunderland, MA.

Tainter, F. H., and Baker, F. A. 1996. Brown spot. Pages 467-492 in: Principles of Forest Pathology, John Wiley and Sons, New York.

Tamura, K., Peterson, D., Peterson, N., Stecher, G., Nei, M., and Kumar, S. 2011. MEGA5: Molecular evolutionary genetics analysis using maximum likelihood, evolutionary distance, and maximum parsimony methods. Mol. Biol. Evol. 28:2731-2739.

Taylor, J. W. 1999. The evolutionary biology and population genetics underlying fungal strain typing. Clin. Microbiol. Rev. 12:126-146.

Thümen, F. 1878. Fungorum Americanorum. Flora 61:177-184.

Walker, A. S., Gautier, A. L., Confais, J., Martinho, D., Viaud, M., Le, P. C. P., Dupont, J., and Fournier, E. 2011. Botrytis pseudocinerea, a new cryptic species causing gray mold in French vineyards in sympatry with Botrytis cinerea. Phytopathology 101:1433-1445. 
Wingen, L. U., Shaw, M. W., and Brown, J. K. M. 2013. Long-distance dispersal and its influence on adaptation to host resistance in a heterogeneous landscape. Plant Pathol. 62:9-20.

Wingfield, M. J., Brockerhoff, E. G., Wingfield, B., and Slippers, B. 2015. Planted forest health: The need for a global strategy. Science 349: 832-836.

Wingfield, M. J., Slippers, B., Roux, J., and Wingfield, B. 2011. Fifty years of tree pest and pathogen invasions, increasingly threatening world forests.
Pages 89-99 in: Fifty Years of Invasion Ecology: The Legacy of Charles Elton. D. M. Richardson, ed. Blackwell Publishing Ltd., Oxford, U.K.

Wolf, F. A., and Barbour, W. J. 1940. Brown spot needle disease of pines. Phytopathology 31:61-73.

Zhan, J., Pettway, R. E., and McDonald, B. A. 2003. The global genetic structure of the wheat pathogen Mycosphaerella graminicola is characterized by high nuclear diversity, low mitochondrial diversity, regular recombination, and gene flow. Fungal Genet. Biol. 38:286-297. 